\title{
Multidisciplinary Approach to the Treatment of an Unusual Crown Fracture after Trauma: Alternative Technique Proposal
}

\begin{abstract}
Guilherme Goulart Cabral-Oliveira, Adriano Rocha Campos, Lanna Cristina Gonçalves da Costa Vieira, Marco André
\end{abstract} de Berredo Pinho, Georgiana Amaral, Cesar dos Reis Perez*

Faculty of Dentistry of University of Rio de Janeiro State (UERJ), Brazil

\begin{abstract}
This case report presents multidisciplinary management of a sub gingival crown-root fracture of a 15-year-old patient referred to the dental trauma clinic with an extensive tooth fracture of the permanent maxillary central incisors after a traumatic injury during a volleyball game. This work aimed to present an alternative approach for complicated dental fracture after trauma obtaining immediate resolution. A unique aspect of the case was that the patient was referred from the semiology clinic without pain and with signs of extensive cracking after 13 days of trauma. However, no endodontic involvement was observed either clinically or radio graphically. After examining a probe, the fracture trace dislocated with pulp exposure and sub-gingival extension. An alternative isolation technique was presented to enable immediate endodontic treatment and restoration of fractured teeth.
\end{abstract}

Keywords: Dental trauma, Endodontic treatment, Composite resin, Rubber dam isolation, Crown fracture, Sports related dental injuries, Anterior teeth

\section{Introduction}

Anterior tooth fracture, resulting from traumatic injuries, presents a close relation to sports, causing functional, esthetic, and psychosocial problems. The maxillary central incisors stand out as the most affected, followed by the maxillary lateral incisors, due to their position in the arch, potentiated by the overjet (characteristic of the young ages) ${ }^{1,2} \mathrm{~A}$ considerable number of these are the result of sports injuries; $30 \%$ of them involve young adolescents because they are more physically active than adults. ${ }^{3-5}$ It is recommended that contact sports athletes (from football, volleyball, basketball, handball, hockey, rugby, martial arts, and others) use safety devices, such as mouth guards, to minimize impacts. ${ }^{6}$ The severity of the traumatic injuries varies in severity from enamel fractures to avulsions. A complicated crown-root fracture is a traumatic dental injury involving the enamel, dentin, cementum, and with pulpal involvement. ${ }^{7,8}$ Crown-root fractures are pretty common and frequently present treatment problems due to the complex nature of the injury, deserving special attention because of the diversity of clinical solutions proposed for the treatment. ${ }^{9}$ An interdisciplinary approach, which involves representatives from pediatric dentistry, endodontics, oral surgery, orthodontics, and restorative dentistry, is obligatory. Probably one of the biggest challenges is the need to solve the problem as quickly as possible to provide functional and aesthetic rehabilitation. ${ }^{10-12}$ Usually, this type of fracture leads the patient to seek treatment immediately due to pain, functional

\begin{tabular}{|l|l|l|l}
\hline \hline Quick Response Code: & *Corresponding author: Cesar dos Reis Perez, Faculty of Dentistry of University of Rio de Ja- \\
neiro State (UERJ), Boulevard 28 de setembro, 157, Vila Isabel, ZIP 20551-030, Rio de Janeiro, \\
RJ, Brazil \\
Received: 18 October, 2021 \\
Citation: Cabral-Oliveira GG, Campos AR, Vieira LCGC, Pinho MAB, Amaral G, et al. Multidis- \\
ciplinary Approach to the Treatment of an Unusual Crown Fracture after Trauma: Alternative \\
Technique Proposal. SOJ Den Oral Disor. 2021;1(3):1-4. DOI: \\
10.53902/SOJDOD.2021.01.000515
\end{tabular}


difficulties and aesthetic inconvenience. This case report aims to show an unusual crown-root fracture without painful expressive symptomatology that had multidisciplinary management using an alternative isolation technique.

\section{Case Report}

A 15-year-old Caucasian boy arrived at the dental trauma clinic after a fall in volleyball game 13 days before complaining that one of his teeth was broken. He said that he went to a public hospital for an emergency consult after the incident, where he was examined clinically, and a radiographic examination was done. Then he was referred to our service. The patient complained of sensibility and aesthetic aspects of tooth 21 . He also noticed a crack and a minor fracture in tooth 11 and another small fracture in tooth 22. He said that the crack in tooth 11 became more evident and darkened after the first few days Figure 1A.

As the patient brought the radiographic examination taken at the emergency care, we could assess the extent of the lesions at that time and a periodontal ligament thickening Figure1B. Clinical examination revealed that the left central incisor was fractured in the middle third of the crown. The lateral incisor was fractured at the incisal angle, involving enamel and dentin without pulp exposure evidence and signs or symptoms of concussion or contusion. Surprisingly, during examination with a probe, it could be noticed that tooth 11 presented separated fragments Figure1C. Although it was not the patient's complaint, tooth 11 presented an extensive fracture extending subgingivally Figure 1D. An impression was made a silicone base impression material (Aquasil; Dentsply, Petropolis, RJ, Brazil) and poured in type IV dental stone (Fugirock, GC Europe, Belgium) to perform a diagnostic waxing during the endodontic procedure time to facilitate the restorative procedure. After local anaesthesia, gentle removal of the fractured fragment was performed; exposing the vital was pulp Figure 1E.

One aspect that distinguished this procedure from a conventional one was the intrinsic difficulty in isolation due to the sub gingival fracture. A modified isolation technique Figure 2A was used with a gingival barrier (Top Dam, FGM, Joinvile, SC, Brazil) to overcome this difficulty. The access was made for pulp removal. A manual crown-down technique was performed to clean and shape up to a K-file \#70 (Maillefer, Baillaigues, Switzerland) using a $5,25 \%$ sodium hypochlorite solution followed by $17 \%$ EDTA. ${ }^{13}$ The root canal was filled with medium gutta-percha points and sealer 26 (Dentsply, Petropolis, RJ, Brazil), completing endodontic therapy in tooth 11 carried out in a single session Figure 2B and Figure 2C.

The isolation was removed for the restorative procedure, and the silicon index was obtained after the waxing Figure 3A. Again, the subgingival aspect of some margins required the adaptation of isolation and restorative techniques. An alternative method was employed: firstly, a thin non-impregnated retraction cord was inserted to avoid blood contamination (Ultrapack \#00, Ultradent, South Jordan, UT, USA), and relative isolation with cotton rolls was performed. After that, a Mylar matrix was gently inserted in the gingival sulcus and stabilized in position with the gingival barrier, allowing the recreation of the lost cervical wall without contamination Figure 3B. The next step was acid etching for 20 seconds for enamel and 10 seconds for dentin (Ultra Etch, Ultradent Products, South Jordan, UT, USA). ${ }^{14}$ The etchant was removed, and the cavity was sprayed with water for 30 seconds, then carefully dried using the blot drying method to maintain a moist surface. Then, adhesive (Adper TM Single Bond, 3M ESPE, St. Paul, MN, USA) was applied with a micro brush following the manufacturer's instructions. The excess was removed with paper points and photocured for $20 \mathrm{sec}-$ onds. ${ }^{14}$ After that, a thin increment of A2 flowable bulk-fill resin (X-tra Base, Voco, Cuxhaven, Germany) was carefully inserted at the gingival wall and photocured for 20 seconds. ${ }^{15}$ The internal part of the pulpal camera was also filled with this material to obtain good internal adaptation and minimum contraction.

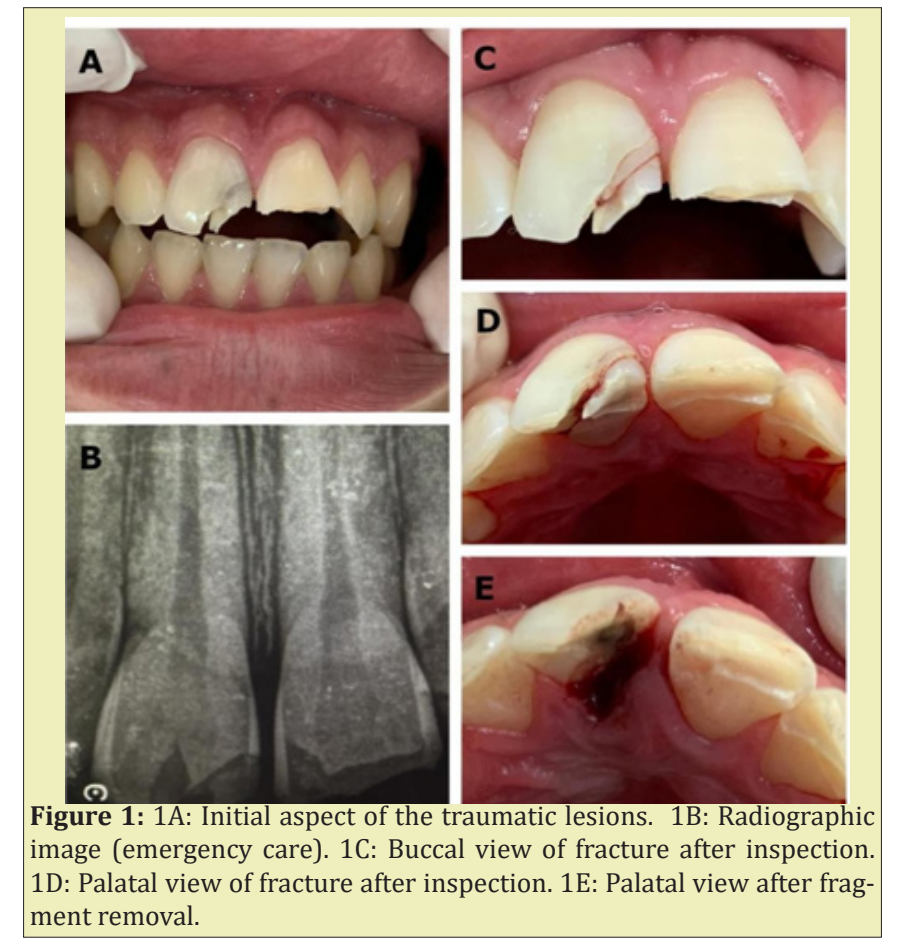

After building the gingival wall, the Mylar matrix and the gingival barrier could be removed Figure 3C, and a silicon index made after the diagnostic waxing was inserted in position. The index enables the recreation of the

incisal contour and the placement of the composite resin. A multilayer technique could be performed beginning with Germany), Figure 3D, after which the index could be removed. A thin layer of enamel-like resin (Brilliant EverGlowA2/B2, Coltène, Langenau, Germany) was inserted to mimic the degree of translucency of the 
tooth enamel of the young patient. Continuing the multilayer technique with freehand sculpting, an opaque dentin shade (Brilliant EverGlow Opaque A1, Coltène, Langenau, Germany) was used to recreate the dentin mamelons, and other between them. The superficial layer was constructed with the translucent shade. ${ }^{16}$ The final aspect of the restorations can be seen in Figure 3E.

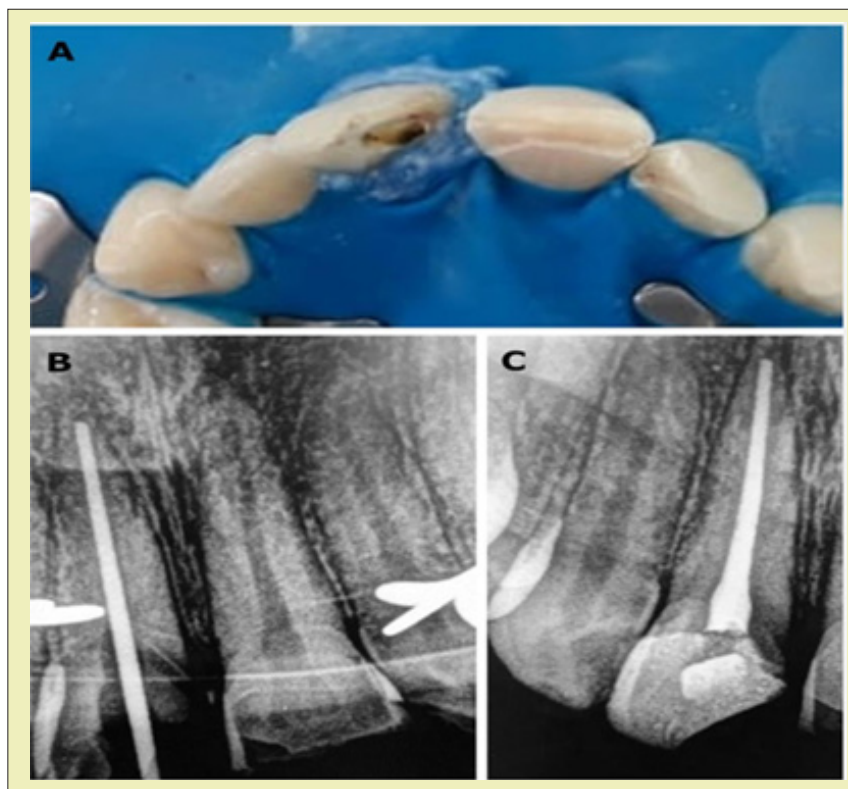

Figure 2: 2A: Modified rubber dam isolation. 2B: Radiographic aspect during endodontic treatment.

2C: Radiographic aspect after endodontic treatment.
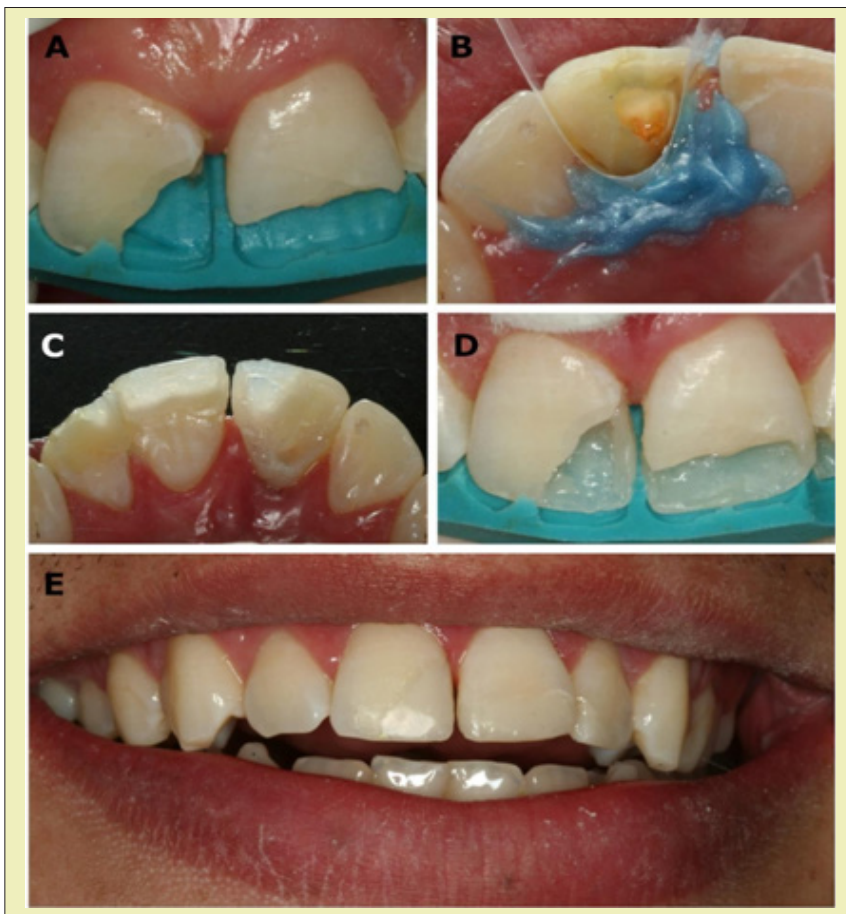

Figure 3: 3A: Silicon index test. 3B: Complex of Mylar matrix and gingival barrier in position. 3C: Palatal aspect of cervical reconstruction. 3D: Palatal and incisal reconstruction. 3E: Final aspect.

\section{Discussion}

Traumatic injuries to permanent teeth are widespread, and many of the injured teeth were untreated or received inadequate treatment. ${ }^{17-21}$ The appearance and position of the anterior teeth have psychological and social impacts on children, and traumatic injuries to the permanent teeth frequently influence them directly. ${ }^{21,22}$ This case report shows a complicated crown fracture which can be defined as an enamel-dentin fracture with pulp exposure, according to the guideline on pediatric restorative dentistry of the American Academy of Pediatric Dental Council on Clinical Affairs. ${ }^{23}$ Despite the intensity of the impact, minimal injury to the dental ligament was observed. A unique character, in this case, was the fact that the patient did not complain of element 11, but of 21, which had exposed dentin. However, after simple probing, the fracture trace moved and demonstrated the extent of the lesion. Considering the affected region, the time elapsed from trauma, and the aesthetic needs, it was decided to perform endodontic treatment and restorations in a single session in a multidisciplinary effort. The endodontic treatment required a modified isolation technique due to the subgingival extension of the fracture. Using a gingival barrier as a subgingival margin sealing agent was efficient to avoid contamination during treatment. ${ }^{15}$

Despite the extent of the fractures, the composite resin was considered the best alternative: it can be well suited for young people because it requires a very conservative technique for performing repairs without a reduction in healthy tooth structure. There are different approaches and technical possibilities for this type of restoration: ${ }^{24}$ from indirect restorations ${ }^{25,26}$ to the use of tooth fragments obtained from bio repositories ${ }^{26}$ or through the recovery of the original fragments. ${ }^{10}$ In this case, we used a submicron hybrid composite with the layering technique. The aesthetic result proved satisfactory, and it was possible to seal the subgingival margin using relative isolation associated with a modified matrix containment technique that had been used in similar. ${ }^{27,28}$ With this technique, it was possible to insert the first increments in the deepest parts of the fracture with a flowable bulk-fill resin aiming at maximum adaptation, and minimum contraction stress. The technique also provides excellent adaptation and requires minimum finishing and polishing procedures.

\section{Conclusion}

The case report presented highlights the importance of a multidisciplinary approach in dental traumatology, showing, through an unusual situation, the need for rapid assessment and intervention, demonstrating that the extent of the injury may be greater than initially expected. Furthermore, it demonstrates alternative techniques of isolation and restoration that can be used in fractures with subgingival margins. 


\section{Acknowledgments}

None.

\section{Funding}

None.

\section{Conflicts of interest}

Author declares that there is no conflict of interest.

\section{References}

1. Lauridsen E, Hermann NV, Gerds TA, et al. Pattern of traumatic dental injuries in the permanent dentition among children, adolescents, and adults. Dent Traumatol. 2012;28(5):358-363.

2. De Souza Cortes MI, Marcenes W, Sheiham A. Impact of traumatic injuries to the permanent teeth on the oral health-related quality of life in 12-14-year-old children. Community Dent Oral Epidemiol. 2002;30(3):193-198.

3. DiAngelis AJ, Andreasen JO, Ebeleseder KA, et al. International Association of Dental Traumatology guidelines for the management of traumatic dental injuries: 1 . Fractures and luxations of permanent teeth. Dent Traumatol. 2012;28(1):2-12.

4. Flanders RA, Bhat M. The incidence of orofacial injuries in sports: a pilot study in Illinois. J Am Dent Assoc. 1995;126(4):491-496.

5. Spinas E, Giannetti L, Mameli A, et al. Dental injuries in young athletes, a five-year follow-up study. Eur J Paediatr Dent. 2018;19(3):187-193.

6. Fernandes LM, Neto JCL, Lima TFR, et al. The use of mouthguards and prevalence of dento-alveolar trauma among athletes: A systematic review and meta-analysis. Dent Traumatol. 2019;35(1):54-72.

7. Andreasen JO, Andreasen FM, Andersson L. Textbook and color atlas of traumatic injuries to the teeth. $5^{\text {th }}$ ed. Hoboken: Wiley-Blackwell; 2018.

8. Castro JCM, Poi WR, Manfrin TM, et al. Analysis of the crown fractures and crown-root fractures due to dental trauma assisted by the Integrated Clinic from 1992 to 2002. Dent Traumatol. 2005;21(3):121126.

9. Andreasen JO, Lauridsen E, Gerds TA, Ahrensburg SS. Dental Trauma Guide: A source of evidence-based treatment guidelines for dental trauma. Dent Traumatol. 2012;28(2):142-147.

10. Valceanu AS, Stratul SI. Multidisciplinary approach of complicated crown fractures of both superior central incisors: a case report. Dent Traumatol. 2008;24(4):482-486.

11. Bate AL, Lerda F. Multidisciplinary approach to the treatment of an oblique crown-root fracture. Dent Traumatol. 2010;26(1):98-104.
12. Merve M, Bilal Y, Huseyin A. Multidisciplinary management of complicated crown-root fracture of an anterior tooth undergoing apexification. Case Rep in Dent; 2015.

13. Torabinejad M, Shabahang S, Bahjri K. Effect of MTAD on postoperative discomfort: a randomized clinical trial. J Endod. 2005;31(3):171-176.

14. Nagarkar S, Theis-Mahon N, Perdigao J. Universal dental adhesives: Current status, laboratory testing, and clinical performance. J Biomed Mater Res B Appl Biomater. 2019;107(6):2121-2131.

15. Perez CR. Alternative technique for Class V resin composite restorations with minimum finishing/ polishing procedures. Oper Dent. 2010;35(3):375-379.

16. Ismail EH. Color interaction between resin composite layers: An overview. J Esthet Restor Dent. 2021;13:1-13.

17. Cortes MA, Marcenes W, Sheiham A. Impact of traumatic injuries to the permanent teeth on the oral health-related quality of life in 12-14-yearold children. Community Dent Oral Epidemiol. 2002;30(3):193-198.

18. Lam R. Epidemiology and outcomes of traumatic dental injuries: a review of the literature. Austral Dent J. 2016;61:4-20.

19. Marcenes W, al Beiruti N, Tayfour D, et al. Epidemiology of traumatic injuries to the permanent incisors of 9-12-year-old schoolchildren in Damascus, Syria. Dent Traumatol 1999;15(3):117-123.

20. Petti S, Tarsitani G, Arcadi P, et al. The prevalence of anterior tooth trauma in children 6-11 years old. Minerva Stomatol. 1996;45(5):213218.

21. Holm EAK. Traumatic dental injuries in a cohort of 16-year-olds in northern Sweden. Endod Dent Traumatol. 1997;13(6):276-280.

22. Vallittu PK, Vallittu AS, Lassila VP. Dental aesthetics a survey of attitudes in different groups of patients. J Dent. 1996;24(5):335-338.

23. Baldwin DC. Appearance and aesthetics in oral health. Community Dent Oral Epidemiol. 1980;8(5):244-256.

24. American Academy of Pediatric Dentistry reference manual 20092010. Pediatr Dent. 2009;31:1-302.

25. Anchieta RB, Rocha EP, Watanabe MU, et al. Recovering the function and esthetics of fractured teeth using several restorative cosmetic approaches. Three clinical cases. Dent Traumatol. 2012;28(2):166-172.

26. Giachetti L, Pace R. Rehabilitation of severely injured anterior teeth in a young patient using ceramic and FRC: a clinical report. Dent Traumatol. 2008;24(5):560-564.

27. Fonseca JTAF, Reis JA, Ribeiro CMZF. Biomimetic approach to extensive fracture of anterior teeth-a case report. Dent Traumatol. 2012;28(3):247-253.

28. Correa Faria P, Alcantara CEP, Caldas Diniz MV, et al. Biological restoration: root canal and coronal reconstruction. J Esthet Restor Dent. 2010;22(3):168-178. 